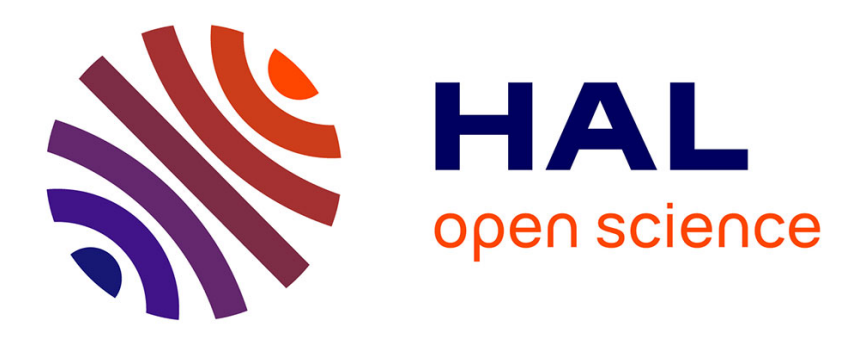

\title{
Growth of cadmium telluride by solvent evaporation
}

B. Lunn, V. Bettridge

\section{To cite this version:}

B. Lunn, V. Bettridge. Growth of cadmium telluride by solvent evaporation. Revue de Physique Appliquée, 1977, 12 (2), pp.151-154. 10.1051/rphysap:01977001202015100 . jpa-00244135

\section{HAL Id: jpa-00244135 https://hal.science/jpa-00244135}

Submitted on 1 Jan 1977

HAL is a multi-disciplinary open access archive for the deposit and dissemination of scientific research documents, whether they are published or not. The documents may come from teaching and research institutions in France or abroad, or from public or private research centers.
L'archive ouverte pluridisciplinaire HAL, est destinée au dépôt et à la diffusion de documents scientifiques de niveau recherche, publiés ou non, émanant des établissements d'enseignement et de recherche français ou étrangers, des laboratoires publics ou privés. 


\title{
GROWTH OF CADMIUM TELLURIDE BY SOLVENT EVAPORATION
}

\author{
B. LUNN and V. BETTRIDGE \\ Physics Dept., University of Hull, N. Humberside, U. K.
}

\begin{abstract}
Résumé. - La croissance de cristaux de tellurure de cadmium peut être effectuée à partir de solutions riches en tellure ou en cadmium, en ajustant graduellement la composition jusqu'à ce que la surface des trois phases est coupée. Dans la technique décrite dans cet article, ceci est atteint en éliminant l'excès de cadmium d'une solution riche en Cd par évaporation : la température d'un réservoir de cadmium est progressivement réduite tout en maintenant l'environnement thermique constant au voisinage de la zone de croissance, ceci conduit à une réduction progressive de l'activité du cadmium dans la solution.
\end{abstract}

\begin{abstract}
Cadmium telluride can be grown from cadmium or tellurium rich solutions of the two elements by gradually adjusting the composition of the solution until the three phase surface is intersected.

This is achieved, in the technique described, by removing excess cadmium from a cadmium rich solution by evaporation. The temperature of a reservoir of cadmium is slowly reduced, whilst maintaining a constant thermal environment in the growth region, thus reducing the activity of cadmium in the solution.
\end{abstract}

1. Introduction. - The need for good quality crystals of cadmium telluride is an established requirement for any device application. The most widely used methods of obtaining such crystals have been the modified Bridgman [1] and the THM [2] techniques described at the previous symposium. These are both solution growth methods in which growth of cadmium telluride takes place by lowering the temperature of a cadmium-tellurium melt containing one component in excess.

An alternative to lowering the temperature of a solution is to remove the excess component by evaporation, the so called solvent evaporation technique (SET). This technique has been widely used for other materials [3] but does not appear to have been exploited for the growth of cadmium telluride.

The operation of the modified Bridgman and solvent evaporation technique can be understood by reference to figure 1. This figure is the P-T projection of the gas-liquid-solid (G-L-S) equilibrium surface in the system $\mathrm{CdTe} / \mathrm{Cd}$ and has been calculated using the Regular Associated Solution model due to Jordan [4].

The line $a-a^{\prime}$ at constant cadmium pressure describes the modified Bridgman method. At $a$ the solution is completely molten and as the temperature is reduced (by moving the solution through a temperature gradient) the G-L-S line is crossed and solid cadmium telluride separates from the solution, until at $a^{\prime}$ solid cadmium telluride only is present.

Two possibilities exist for the solvent evaporation technique. The heating of the solution to remove excess solvent has been discussed previously by Lorentz [5]. The second method is described in Figure 1 by the line $b-b^{\prime}$. At $b$ the solution is comple-

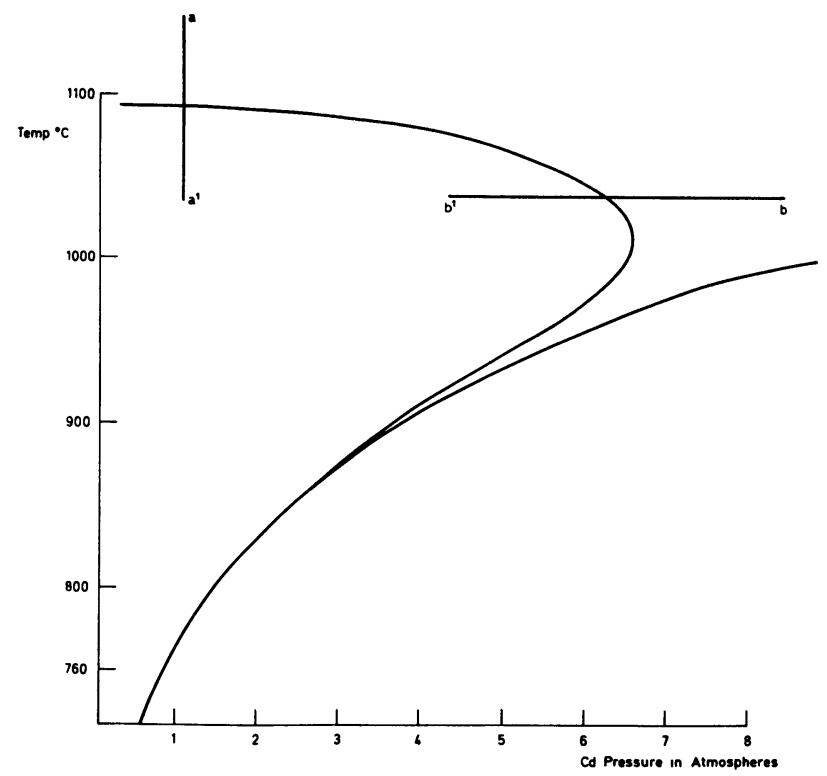

Fig. 1. - P-T projection of the gas-liquid-solid equilibrium surface in the system $\mathrm{CdTe} / \mathrm{Cd}$.

tely molten, but if the pressure of cadmium is reduced (by evaporation) the solution changes isothermally until again the G-L-S line is crossed and solid cadmium telluride is formed. By maintaining the pressure at $b^{\prime}$ the cadmium distils completely from the solution.

The main advantages of this latter technique are that no mechanical movement of the system is required and the thermal environment of the growing crystal remains constant. In principle, crystal growth under near-isothermal conditions is possible and thus leads 


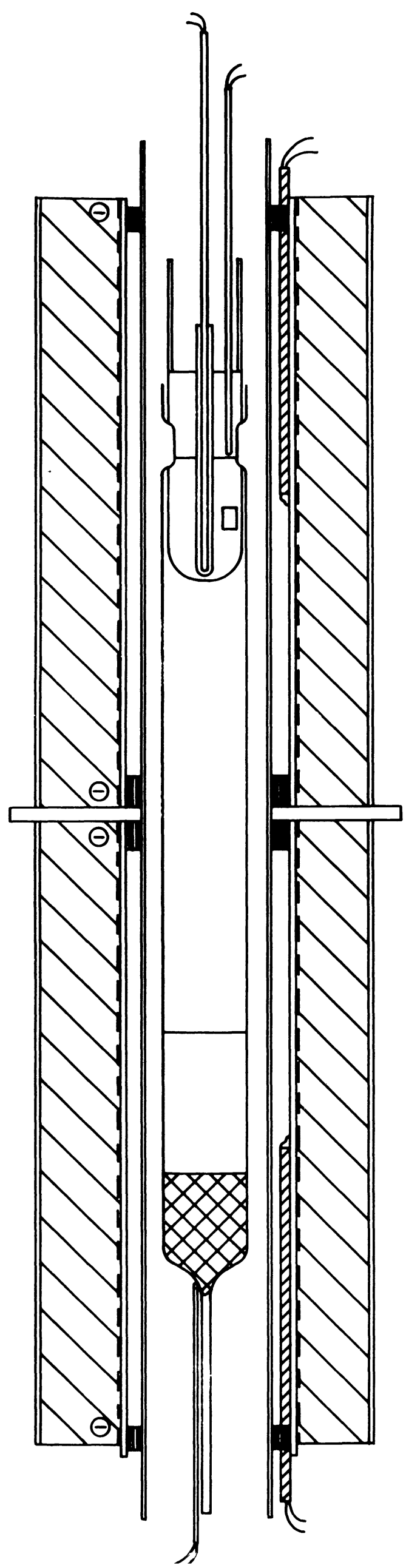

to the further advantage that the concentration of native defects and impurities should be uniform throughout the crystal.

The disadvantage, however, of any isothermal solution technique arises from the possibility of the occurrence of constitutional supercooling and solvent inclusion. This problem becomes more acute when growth takes place from very non-stoichiometric solutions and for this reason the work described in the present paper has been confined to growth from solutions of composition $0.5<X_{\mathrm{Cd}} \leqslant 0.61$, i. e. at temperatures above $\sim 1020^{\circ} \mathrm{C}$.

2. Experimental. - 2.1 SynTHEsIS. - The compound is synthesised directly from the elements.

The starting materials are $6 \mathrm{~N}$ Vielle-Montagne cadmium shot and $6 \mathrm{~N}$ Koch-Light tellurium bar. The cadmium, as received, shows evidence of surface oxidation and is etched in an Aristar nitric/absolute alcohol mixture. The tellurium is not treated chemically because of the risk of introducing undesirable impurities (e. g. chlorine from a hydrochloric acid etch).

The synthesis is done in an evacuated horizontal silica tube which has been coated with a pyrolysed carbon film obtained by dissociating high purity propane (Air Products, Instrument grade). Initially the system is held for a day with each end of the tube at $\sim 800^{\circ} \mathrm{C}$ and then the temperature of the furnace is raised slowly over a further two days until the temperature of each end has reached $\sim 1030^{\circ} \mathrm{C}$. These conditions are maintained for two more days and the furnace is then switched off. Using this technique it is possible to synthesise up to $300 \mathrm{gms}$ of material without explosions and the end product is found as a solid boule at each end of the system.

2.2 Growth. - The growth furnace is a vertical two zone resistance heated system, with provision for a short third heated zone between the two main elements. Growth takes place in the lower zone and the cadmium pressure over the melt is controlled by the upper (reservoir) zone. Temperature stability is better than $\pm 0.1^{\circ}$ at $1100^{\circ} \mathrm{C}$.

The temperature profile in the growth region is taken using a tube identical to the growth tubes but with a re-entrant thermocouple. In this way the profile obtained is very close to the profile existing in the system during a growth run. The temperature gradient for a typical run varies from $12^{\circ} \mathrm{C} / \mathrm{cm}$ at the coolest part of the growth zone to $\sim 4^{\circ} \mathrm{C} / \mathrm{cm}$ at the hottest. This is entirely consistent with the requirement that the further from stoichiometry the growth takes place, the steeper should be the temperature gradient. The actual temperatures in the growth region are typically $1040^{\circ} \mathrm{C}$ at the tip of the crystal and $1080^{\circ} \mathrm{C}$ at the end.

The growth system is shown in figure 2 . It is a vitreous silica tube ( $\sim 20 \mathrm{~mm}$ ID) which is coated in

FIG. 2. - Growth tube and furnace. 
the growth region with a film of pyrolysed carbon. The tube is loaded with cadmium telluride lumps and cadmium shot, evacuated to better than $10^{-7}$ torr and sealed with the thimble shown in the upper part of the tube. This thimble, which is closed at both ends, has a slot cut in the side and serves as the cadmium reservoir. The thimble includes a re-entrant thermocouple well to monitor the temperature within the cadmium melt.

During the growth run it is common practice to monitor the temperature of the coolest part of the growth region (i. e. the tip of the boule), the coolest part of the reservoir (external to the growth system, but in intimate contact with it) and the inside of the cadmium reservoir. The reason for two monitoring thermocouples on the reservoir is that a temperature gradient exists along the reservoir element. This gradient is small at the start of the run, but increases as the temperature of the reservoir element is decreased. Since the pressure of the reservoir is an important parameter in the growth method, it is necessary to know the temperature of the reservoir. At the start of the run it is assumed that the temperature of the coolest part of the reservoir $\left(980^{\circ} \mathrm{C}\right)$ determines the cadmium pressure and is chosen to ensure the whole growth region is molten. (This has been verified experimentally by quenching a small capsule and charge from these initial conditions). The system is allowed to remain in this condition overnight to ensure complete dissolution of the cadmium telluride, during which time any excess cadmium distils into the reservoir and provides the cadmium pressure.

The temperature of the reservoir is then reduced continuously at the rate of $\sim 3^{0}$ per hour. This disturbs the equilibrium in the system and cadmium evaporates from the solution. At the end of the run all the cadmium is found at the bottom of the reservoir (i. e. $\sim 20^{\circ} \mathrm{C}$ higher than the coolest part of the system) and it is assumed that this cadmium controls the pressure. The reservoir element temperature is lowered until the temperature inside the cadmium is typically $750^{\circ} \mathrm{C}$.

The growth rate in the system is not constant with linear cooling of the reservoir temperature. Table I shows how the equilibrium growth rate varies in a typical run.

At the end of the growth period the furnace is cooled either using predetermined rates for the growth and reservoir zones or by simply switching off both elements. Care has to be taken to ensure the conditions in the system do not move outside the restrictions of the G-L-S curve at the lower temperatures nor too near the $P_{\min }$ line.

Using this system good quality single crystals up to $20 \mathrm{~cm}^{3}$ ( $2 \mathrm{~cm}$ diam. $\times 6 \mathrm{~cm}$ long) and containing only small regions of twinning have been grown. Larger volume crystals can only be grown by using larger diameter tubes or much shallower gradients, because of the nature of the P-T diagram. Orientation of a typical boule shows the cylindrical axis to be approximately $17^{\circ}$ off [100] in the [02 1 ] direction. Very often porosity can be found in the last to grow section of otherwise good crystals, but is not reproducible even in crystals grown under apparently identical conditions.

2.3 ChARACTERISATION. - The crystals are characterised for their optical and electrical properties at room temperature.

Examination using the infra-red microscope shows no second phase precipitates and no evidence of constitutional supercooling has been seen. Etch pit studies [6] on cleaved (110) surfaces give dislocation densities of $10^{2}-10^{3} \mathrm{~cm}^{-2}$ but no systematic variation with position in the boule has been found.

The crystals show the expected absorption edge for undoped material at $\sim 1.46 \mathrm{eV}$ and transmit out to $28 \mu$.

Resistivity measurements have been made using the van der Pauw [7] method after applying contacts to freshly cleaved surfaces. The crystals are p-type with resistivities varying between 1 and $10^{7} \Omega \mathrm{cm}$ depending on the method of cooling. The lowest resistivities are found in crystals which have been cooled by decreasing the growth zone temperature at the cadmium pressure existing at the end of the growth time, and then switching off the furnace when the two elements are approximately at the same temperature. The highest resistivities have been obtained when, instead of switching off the furnace, the two elements are programmed to maintain the P-T conditions within the G-L-S curve and at pressures greater than the minimum pressure for all temperatures. No significant variation of resistivity with position is found in any one crystal, however.

Hall measurements have been possible only on material with resistivity $\leqslant 10^{3} \Omega \mathrm{cm}$. Room temperature mobilities of $\sim 80 \mathrm{~cm}^{2} \mathrm{~V}^{-1} \mathrm{~s}^{-1}$ have been obtained.

Carrier densities on higher resistivity material have been obtained by the differential capacitance method and using either an evaporated aluminium contact or a mercury probe [8]. The measurements using the mercury probe have proved most useful in the

\section{TABLE I}

(« equilibrium » growth rates)

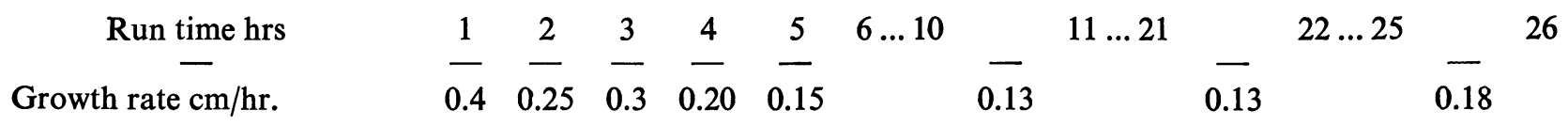


range $10^{13}-10^{15}$ carriers $/ \mathrm{cm}^{3}$ since probe areas of $\sim 10^{-3} \mathrm{~cm}^{2}$ are used. Variations in carrier density have been observed in $1 \mathrm{~cm}^{2}$ slices cleaved from different regions of a crystal although variations across any one slice are small. This work is in its early stages, however, and no systematic investigation of carrier density versus position has been attempted.

No chemical analysis of the crystals is available at present, since the level of impurity is below the limits of detection of our emission spectrograph.

3. Discussion. - The solvent evaporation technique is capable of producing good quality material using the experimental conditions described above. However, since one potential advantage of the method is the possibility of using near isothermal growth conditions, the presence of a temperature gradient along the boule is an undesirable feature, even though the difference of $\sim 40^{\circ} \mathrm{C}$ over $6 \mathrm{~cm}$ is much lower than is usual in Bridgman growth. Attempts have been made to grow crystals in a shallower gradient $\left(\sim 1.5^{\circ} \mathrm{C} / \mathrm{cm}\right)$ but porosity in the boule then becomes a serious problem and up to two thirds of the boule can become porous.

The cause of porosity at the end of a boule is not known. It is surprising that it occurs in the very regions where, if the melt is in equilibrium with the reservoir vapour pressure, the deviation from stoichiometry is least and hence problems of constitutional supercooling should be minimised. This suggests that the melt is not in fact in equilibrium with the reservoir. There are two possible reasons why this should happen-either the vapour pressure immediately above the melt is higher than the reservoir pressure or there has been an accumulation of cadmium in the melt as the run progresses. The first situation could arise if the cadmium rejected from the melt is not removed efficiently to the reservoir. The accumulation in the melt could happen if material rejected from the growing interface is not removed at the melt surface at the same rate. This is more likely to happen in a quiescent melt, i. e. there is little or no convection. If the conditions in the melt are considered it is seen that thermal convection is ruled out by the adverse temperature gradient. Solutal convection is also unlikely because the equilibrium activity of cadmium (the most dense material in the system) decreases towards the top of the solution. The transfer of material from the growing interface to the melt surface is thus diffusion controlled and the possibility to accumulate excess cadmium exists. This problem is a matter for further investigation.

The method has obvious possibilities for the growth of doped crystals and for growth from tellurium rich solutions. The rate of loss of solvent can also be controlled using other techniques such as small diameter orifices between solution and reservoir or by the pressure of an inert gas. For growth at lower temperatures than used here it is interesting to observe that the growth will occur first at the highest temperature in the system.

The method also has possible application in thegrowth of other II-VI compounds and for the growth of epitaxial layers using the liquid phase epitaxy technique.

Acknowledgements. - The authors wish to thank the Science Research Council for financial support for this work, Mr. G. L. Bucknell for synthesising the material and Drs. B. Tuck and P. Jay (Electrical and Electronic Engineering Department, University of Nottingham, UK) for allowing us to use their mercury probe differential capacitance apparatus.

References

[1] Kyle, N., Proceedings of the International Symposium on Cadmium Telluride (Strasbourg 1971), Eds. P. Siffert and A. Cornet.

[2] Bell, R. O., Hemmat, N., Wald, F., Phys. Stat. Sol. (a) 1 (1970) 375.

[3] Crystal Growth from high temperature solutions D. Elwell, H. J. Scheel (Academic Press London) 1975.

[4] (a) JoRdAN, A. S., Met. Trans. 1 (1970) 239. (b) JoRdAN, A. S., ZuPP, R. R., J. Electrochem. Soc. 116 (1969) 1285.

[5] Lorenz, M. R., J. Appl. Phys. (U. S. A.) 33 (1962) 3304.

[6] Inoue, M., Termato, I., Takayanagi, S., J. Appl. Phys. 33. (1962) 2578.

[7] VAN DeR Pauw, L. J., Philips Res. Repts. 13 (1958) 1.

[8] Hammer, R., Rev. Sci. Instrum. 38 (1967) 564. 